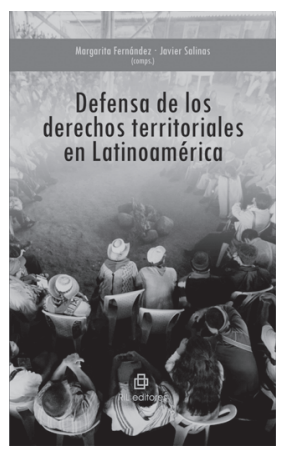

\title{
Margarita Fernández y Javier Salinas (compiladores). Defensa de los derechos territoriales en Latinoamérica.
}

\author{
Santiago de Chile: RIL editores / Programa Ciudadanía y \\ Gestión Pública, Universidad de Los Lagos, Corporación para \\ la Innovación en Ciudadanía, 2012. 515 p.
}

\author{
José Carlos Barrio de Pedro ${ }^{1}$
}

El libro consta de quince capítulos precedidos por una pequeña presentación ( $M$. Fernández) y una introducción (M. Fernández y J. Salinas) titulada "La defensa de los derechos desde las comunidades locales en Latinoamérica: experiencias y lecciones de la acción territorial". En estas, queda establecida la temática del libro y su estructura ordenada en una serie de estudios de casos. Respecto a la temática, se trata de analizar las actuales disputas por derechos a un uso más justo e igualitario (es decir más democrático, transparente e inclusivo) de los recursos y bienes públicos (territorios, recursos naturales, medio ambiente), con fines de desarrollo territorial. Los estudios de casos se refieren a espacios que se confrontan a equivalentes problemas de crecimiento económico y de sobreexplotación de recursos, bajo marcos normativos e instrumentos de políticas relativamente frágiles.

Si nos referimos al contexto que justifica el trabajo y a su contenido en términos generales, queda establecido que "las opciones políticas de privilegiar una estrategia de crecimiento económico, amparada en un supuesto de provisión de mayores empleos, pero carente de componentes de sustentabilidad y justicia social, que opera en un marco de decisiones altamente centralizado, ha significado legitimar reglas, normas y políticas que asientan grandes desequilibrios de poder y que se aplican en un contexto de gobernabilidad restringida y un déficit de participa-

\footnotetext{
1 Centro de Estudios del Desarrollo Local y Regional, Universidad de Los Lagos (Chile).

E-mail: josecarlos.barrio@ulagos.cl
}

ción e incidencia de la ciudadanía, de espacios públicos y transparencia". Entonces, "en ese marco, resulta relevante el levantamiento y visibilización de la problemática para poner en discusión nuevos arreglos regulatorios y de participación, que favorezcan el reconocimiento de los actores que comparten un territorio y en pro de una resolución pacífica de los conflictos". Los trece casos seleccionados (citados en la introducción como ocho en Chile y cinco en Perú y México, de alcance local, provincial o regional, con actores comunitarios, étnicos, funcionariales públicos y empresariales) dan cuenta del ejercicio de una ciudadanía activa, con propuestas que han alcanzado ciertos logros. Asimismo, exponen dilemas sobre el desarrollo y las reglas que lo rigen (los marcos normativos e instrumentos de políticas), cuestionando definiciones relevantes sobre regulación económica y ambiental, descentralización, transparencia e inclusión. En estas experiencias "se expresa una pugna relativamente invisibilizada, que carece de espacio público para debatir aspectos fundamentales sobre lo que cada país requiere para alcanzar una mayor justicia social". Queda establecido, además, que el desarrollo territorial libremente elegido, inclusivo y sostenible encuentra grandes dificultades en su realización, como la presión de grandes actores económicos, las lagunas político-administrativas y normativas, la propia definición y distribución de los recursos públicos, la falta de medios o de capacidades de administración de los propios actores, etc.

Se trata de un libro voluminoso, que contiene gran cantidad de información con diferente nivel de generalización y una natural redundancia en detalles referidos a los 
distintos estudios de caso. Aunque cada uno de los (tres) grupos de capítulos culmina con un capítulo de síntesis destinado a sistematizar la información, se hace deseable una "sistematización de la sistematización" que, tal vez, hubiera podido realizarse parcialmente en un capítulo de conclusión, no disponible. Sin embargo, el material podría con interés servir de base para un "manual sobre el desarrollo territorial inclusivo", donde se pudieran sistematizar los aportes de las diferentes situaciones político-legislativas y de los diferentes tipos de conflicto y estudios de caso. Más allá de estas observaciones, cabe señalar que los tratamientos de casos o experiencias, sí han beneficiado de una cierta envoltura metodológica en cuanto a la estructura de los ítemes abordados:

El contexto territorial. Se ocupa de las dimensiones geográficas, históricas, políticas y administrativas, así como de la caracterización de los actores, las dinámicas socioeconómicas y los aspectos identitarios.

El desarrollo de la experiencia. Consiste en la caracterización de los conflictos y el análisis de sus procesos de desarrollo (historia, etapas, causalidades, actores y roles), para lo cual emplea un doble enfoque, "desde abajo" (estrategias, procesos y propuestas de actores; soportes endógenos y exógenos; instrumentos y acciones empleados; conflictos, negociaciones y acuerdos) y "desde arriba" (actores decisores, normativas e instrumentos de política, espacios e instancias interpelados desde la práctica local).

Los logros de proceso y los resultados finales. Describe sus características y su formalidad, los aspectos no resueltos o pendientes, y los dilemas planteados por las soluciones alcanzadas. Se ocupa de lo referente a la experiencia en sí misma (reparación de daños, compensaciones obtenidas, efectos en las propias comunidades), al impacto a nivel local (evaluación de la calidad de la participación en las decisiones tomadas; generación de capacidades locales; cambios en la inclusión social y en la situación de vida de las personas; efectos en la identidad local, en el desarrollo de las organizaciones y en el ejercicio de la ciudadanía), a nivel de las instituciones (arreglos institucionales que dan salida o proyectan los conflictos hacia otros escenarios) y a nivel general (incidencia en las condiciones de aplicación de los marcos legales o en las orientaciones de políticas y programas públicos; cambios en la institucionalidad pública en lo referente a nuevas leyes, reglamentos o programas).

Los aprendizajes relevantes. Muestra los factores críticos y las prácticas empleadas que potencian o limitan los niveles de logro y resultados, describe los enfoques de actores, así como el "saber hacer" acumulado (respecto a estrategias, relaciones, alianzas e instrumentos), y se interroga sobre las nuevas bases y dinámicas en curso (positivas o negativas) sobre las que pueda operar este tipo de procesos en un futuro.

Como hemos indicado, los capítulos del libro se agrupan en torno a tres categorías o tipos de conflictos analizados. En primer lugar, los que desarrollan las comunidades indígenas por el reconocimiento de sus derechos territoriales y de su autonomía. Como señala Jorge Contesse en su capítulo de sistematización referido a los casos de Perú, Chile y México ("Derechos territoriales y autodeterminación indígena: desafíos para la inclusión"), se observan tres patrones comunes a los diferentes casos: la articulación "desde abajo" (a partir de las propias experiencias vitales, jurídicas y políticas de las comunidades indígenas), la utilización de cauces institucionales (como forma de dar vida a las demandas de estos grupos) y la interacción constructiva (con, y no en contra del Estado). En todos los casos, las posibilidades de éxito de los procesos reivindicativos no descansan en la mera adopción de instrumentos jurídicos, sino en la práctica cotidiana de los procesos inclusivos, enmarcada en canales institucionales y en un modelo de trabajo constructivo con el Estado. Se genera así una reconstrucción de los estándares normativos, mediante creación, reinterpretación y apropiación de las normas referidas a las promesas de autodeterminación y sus implicaciones. En esta categoría de análisis se sitúan los capítulos "Incidencia del movimiento indígena en la ley que crea el espacio costero marino de los pueblos originarios en Chile" (por Gonzalo Delamaza y Fabián Flores), "Protegiendo sus territorios: coadministración entre comunidades atacameñas y el estado chileno en el Valle de la Luna" (Antofagasta, Chile; por Laura M. Seelau y Ryan Seelau) y "Políticas de 
reconocimiento y gobernabilidad comunitaria: el caso del municipio de usos y costumbres de Santa Ana del Valle, Oaxaca" (México, por Jorge Hernández Díaz), además de un capítulo introductorio titulado "Entre todo y nada: la libre determinación indígena y los espacios para su ejercicio en Chile" (por Laura M. Seelau y Ryan Seelau).

En segundo lugar, los conflictos que inciden sobre comunidades indígenas, campesinas y rurales en torno a la defensa de recursos del territorio frente a grandes empresas extractivas o megaproyectos. El capítulo de sistematización de Alejandro Diez se refiere a los casos analizados en Chile ("Conflicto e intermediación ausente entre comunidades étnicas, campesinas y rurales, y grandes empresas mineras. Cuatro casos para comentar"), en los cuales se evidencia una legislación que favorece la atracción de capitales antes que su regulación, así como la fragilidad y parcialidad de los marcos regulatorios y administrativos (funcionarios y organismos del Estado), respecto a la demanda social y local de evaluación y control socioambiental de las actividades extractivas y proyectos. En consecuencia, el "triángulo ideal" de equilibrio Estado-empresas-comunidades no se verifica, sino que el Estado desaparece o se aproxima al vértice de la empresa, tanto por efecto de la regulación favorecedora de la inversión, como por efecto de la sustitución de la acción del Estado por la empresa como promotor del desarrollo local (lógicas de "Responsabilidad Social Empresarial"). En lugar de un intercambio armónico empresa-comunidad, se produce entonces una situación de conflicto en condiciones desiguales. Este tipo de pugnas viene ilustrado por los capítulos "La comunidad Aymara de Cancosa y los acuerdos con la compañía minera Cerro Colorado" (Tarapacá, Chile; por Javier Salinas), "Dilemas de poder y autonomía en las disputas ambientales entre la comunidad de Cuncumén y Minera Los Pelambres" (Coquimbo, Chile; por Margarita Fernández y Fernando Krauss), "El proyecto Tres Valles de la Minera Valle en Salamanca" (Coquimbo, Chile; por Moira del Ponte Flores) y "Minera Dayton, Andacollo: cultura minera y desarrollo sustentable" (Coquimbo, Chile; por Karla Maas Wolfenson). También incluye un capítulo sobre "Constitución de la Agencia Social Indígena: Ios pueblos Secoya y Machiguenga en el Perú" (por Martha Rodríguez Achung, Emilio Rojas Rimachi y Félix Lossio Chávez).

En tercer lugar, los conflictos que se producen en territorios vulnerables, entre actores locales, comunidades rurales e instituciones públicas, en pro de la redistribución de recursos públicos y de una visión descentralizada y autodeterminada del desarrollo. La sistematización de estos casos situados en Chile y México corre a cargo de Daniel Cravacuore ("La defensa de los derechos territoriales en América Latina: el papel de los gobiernos locales"), el cual señala que los casos reflejan acciones reivindicativas de carácter campesino, étnico-cultural o territorial, referidas a una visión a la vez integral y propia de la promoción del desarrollo, y sobre las cuales cabe destacar el carácter complejo del proceso de concertación, su naturaleza efímera y el papel dinámico de los actores no estatales en distintos momentos de la política pública (de receptores pasivos a sujetos de interpelación y constructores de alternativas). En estas situaciones, el predominio de la lógica del Estado central pone en evidencia las carencias de la descentralización (empoderamiento de los gobiernos locales) y de las políticas públicas para territorios vulnerables dirigidas "desde arriba". Además, dentro de un mismo Estado los reconocimientos de derechos aparecen desiguales y sus resultados dispares, ya que dependen más de la capacidad de incidencia de los actores locales y de sus alianzas, que de otros factores. Los conflictos analizados se distribuyen en los capítulos "El desarrollo territorial ausente en el Plan Chiloé: la desigual negociación entre un territorio fragmentado y un Estado centralizado" (Chiloé, Chile; por Gonzalo Delamaza), "La disputa por la política regional de desarrollo rural de la región de Coquimbo" (Chile, por Fernando Krauss) y "El sector Zoogocho: una experiencia Zapoteca de colaboración intercomunitaria" (Oaxaca, México; por Jorge Hernández Díaz).

Para terminar, el libro recoge algunas ideas generales que bien pudieran servir de conclusión a sus contenidos. Por una parte, la experiencia muestra la complejidad dinámica de los procesos de desarrollo territorial inclusivo y sostenible y de los conflictos asociados, así como la complejidad del desarrollo y de la aplicación de políticas públicas respecto a los conflictos e intereses privados (inclusive en términos de delimitación y gestión de 
lo propiamente público y privado). En realidad, estamos hablando de la complejidad del ajuste entre lo social-económico (el desarrollo armónico de los sistemas globales-locales o "glocalización", y de los sistemas productivos relacionados con la expansión del capitalismo) y lo social-político (la democracia participativa como marco de organización y de redistribución del poder). La reflexión profunda sobre los tópicos presentados resulta una asignatura pendiente no solo de los académicos sino, especialmente, de los decisores políticos y de los propios implicados en los procesos de desarrollo.

Por otra parte, si bien la aplicación de políticas de desarrollo territorial requiere de instrumentos de planificación y de ordenamiento territorial, estas políticas e instrumentos no pueden ser definitivos porque los territorios, sus sociedades y la visión de sus actores son dinámicos. En consecuencia, se requiere una profundización democrática que haga posible la participación permanente e inclusiva de todos los actores territoriales, en la regeneración y gestión de las políticas que les afectan. En este sentido, Daniel Cravacuore (capítulo "La defensa de los derechos territoriales en América Latina: el papel de los gobiernos locales") destaca la necesidad de impulsar Estados más activos y comprometidos con lo territorial y con la promoción de los derechos de los sectores vulnerables, fortalecer la descentralización con el fin de contar con gobiernos locales con mayores capacidades institucionales, ampliar los espacios de concertación social, vigorizar a la sociedad civil con mayores niveles de decisión política y más oportunidades de intervención.

Nos quedaría por completar nuestra propuesta metodológica de elaboración de un "manual sobre desarrollo territorial inclusivo", por el planteamiento de interrogantes de investigación aplicada a los cuales el libro no responde de manera unificada puesto que ello no entra en sus objetivos iniciales. Ponemos algunos ejemplos de interrogantes cuya consideración puede ser tan pertinente en términos generales, como aplicable a cada uno de los casos analizados:

En el ámbito de los derechos y deberes. ¿Derecho territorial significa propiedad, o simplemente acceso regulado a un bien pú- blico en cantidad y calidad suficiente? ¿Está clara la separación entre propiedad y acceso, cómo delimitamos lo privado respecto a lo público? ¿Quién cuida de ese bien público y garantiza su durabilidad/perennidad? Hablamos de derechos territoriales pero, iy los deberes territoriales?

En lo relativo a las contradicciones entre proyecto territorial e interés particular. Ante las intervenciones, inversiones o proyectos, de origen privado o público, ¿cabe pensar en términos de oposición frontal o de oportunidad de desarrollo? Si oposición, ¿qué proyecto territorial oponemos, a qué conflictos internos nos enfrentamos? Si diálogo, ¿qué oportunidad puede significar, para quién?

En lo referente a la especificidad de las situaciones. ¿Los derechos (y deberes) territoriales son algo aplicable de manera sustancialmente diferente a las comunidades indígenas respecto a las otras colectividades "campesinas-rurales-locales"? ¿Hasta qué punto esa diferencia es pertinente? ¿Qué otras diferencias entre tipos de casos cabe considerar?

Un cuarto tipo de conflicto por analizar: los derechos territoriales de los "sin tierra". ¿No cabe interrogarse sobre derechos (y deberes) territoriales para las poblaciones más pobres y marginadas dentro mismo de las comunidades rurales o campesinas, aquellas que ni siquiera tienen los medios para hacerse partícipes de los conflictos declarados? Dichas poblaciones, ¿no son incluso mayoría en muchos de los casos? ¿Qué pasa específicamente con la participación femenina, o por grupos de edad? ¿Qué pasa con los derechos territoriales de las poblaciones urbanas o suburbanas, cuya implicación laboral en actividades de subsistencia, o en los sectores de servicios, industria o construcción, o más aún sin actividad alguna, les desvincula (aparentemente) de todo derecho territorial?

En términos de razonamiento empírico de carácter sistémico. ¿Cómo contener, gestionar y dialogar con lo global a partir de lo territorial (fenómenos de escala y temporalidad en el ámbito de la "glocalización")? ¿Cómo se posicionan los actores ante el sistema "capital-trabajo-sociedad de consumo-Estado"? ¿Y ante el sistema ambiental y de recursos naturales públicos? 